\title{
Immunochemical Studies of Plasma Kallikrein
}

\author{
Andrantr Bagdasarian, Biswajti Lahiri, Richard C. Talamo, Pat Wong, and \\ ROBERT W. CoLman \\ From the Coagulation Unit, Hematology-Oncology Section, Department of \\ Medicine, University of Pennsylvania Medical School, Philadelphia, Pennsylvania 19104 \\ and the Department of Pediatrics and Medicine, Harvard Medical School, \\ Boston, Massachusetts 02115
}

\begin{abstract}
A B S T R A C T A monospecific antibody against human plasma kallikrein has been prepared in rabbits with kallikrein further purified to remove gamma globulins. The antisera produced contained antikallikrein and also anti-IgG, in spite of only $8 \%$ contamination of kallikrein preparation with IgG. The latter antibody was removed by adsorption of antisera with either Fletcher factordeficient plasma or with purified IgG. Both kallikrein and prekallikrein (in plasma) cross-react with the antibody with no apparent difference between the precipitation arcs developed during immunoelectrophoresis and no significant difference in reactivity when quantified by radial immunodiffusion.
\end{abstract}

Kallikrein antibody partially inhibits the esterolytic and fully inhibits the proteolytic activity of kallikrein. In addition, the antibody inhibits the activation of prekallikrein, as measured by esterase or kinin release. The magnitude of the inhibition is related to the molecular weight of the activator used. Thus, for the four activators tested, the greatest inhibition is observed with kaolin and factor $\mathrm{XII}_{\Delta}$, while large activator and the low molecular weight prekallikrein activators are less inhibited.

With the kallikrein antibody, the incubation of kallikrein with either plasma or partially purified $\mathrm{C} \overline{1}$ esterase inactivator results in a new precipitin arc, as detected by immunoelectrophoresis. This finding provides physical evidence for the interaction of the enzyme and inhibitor. No new arc could be demonstrated between kallikrein and $\alpha_{2}$-macroglobulin, or $\alpha_{1}$-antitrypsin, although the concentration of free kallikrein antigen decreases after interaction with the former inhibitor.

By radial immunodiffusion, plasma from healthy indi-

Dr. Bagdasarian is the recipient of special Postdoctoral Fellowship HL52189 from the National Institutes of Health. Drs. Talamo and Colman are the recipients of Career Development Awards AM31937 and HL48075, respectively.

Received for publication 10 April 1974 and in revised form 5 August 1974. viduals contained $103 \pm 13 \mu \mathrm{g} / \mathrm{ml}$ prekallikrein antigen. Although in mild liver disease, functional and immunologic kallikrein are proportionally depressed, the levels of prekallikrein antigen in plasma samples from patients with severe liver disease remains $40 \%$ of normal, while the functional kallikrein activity was about $8 \%$. These observations suggest that the livers of these patients have synthesized a proenzyme that cannot be converted to active kallikrein.

\section{INTRODUCTION}

Plasma kallikrein is a proteolytic enzyme that releases the nonapeptide bradykinin from the plasma $\alpha_{2}$-globulin kininogen. Bradykinin, when present systemically in nanogram amouts, profoundly lowers the blood pressure and, when locally injected, mimics many of the features of the inflammatory response (1). Kallikrein exists in a precursor form, prekallikrein, which is converted to the active protease by factor $\mathrm{XII}_{\mathbf{\Delta}}$ (Hageman factor) and its proteolytically produced derivatives (2-5). Assays for kallikrein and prekallikrein have been based on the action of the enzyme on synthetic substrates (6) or its ability to release bradykinin (7). It seemed desirable also to measure prekallikrein immunochemically to observe fluctuations of the protein as well as the enzymatic acitvity in disease and to ascertain whether nonfunctional forms of kallikrein might characterize congential or acquired disorders.

This study describes the further purification of kallikrein (8) and the use of such a preparation and plasma congenitally lacking prekallikrein (9) to obtain a monospecific precipitating antibody to prekallikrein and kallikrein. The interaction of the antibody with prekallikrein is assessed by its ability to inhibit the conversion of prekallikrein to kallikrein and the effect on kallikrein is measured by inhibition of the proteolytic and esterolytic activity of kallikrein. The antibody is also used as a tool to demonstrate complex formation between kallikrein and some of its natural inhibitors. Finally, de- 
velopment of an immunochemical assay permitted assessment of changes in kallikrein antigen level in liver disease.

\section{METHODS}

Reagents. L-tosyl arginine methyl ester (TAMe) ${ }^{1}$ was purchased from Sigma Chemical Co., Inc., St. Louis, Mo., and dissolved in $0.1 \mathrm{M}$ sodium phosphate containing 0.15 $\mathrm{M} \mathrm{NaCl}, \mathrm{pH}$ 7.65. Agarose was purchased from Sigma Chemical Co. Special agar-noble was obtained from Difco Laboratories, Detroit, Mich. Complete Freunds' adjuvant was obtained from Difco. Polystyrene dishes for immunodiffusion were obtained from Hyland Div., Travenol Laboratories, Inc., Costa Mesa, Calif. Sephadex G-200 and CM50 Sephadex beads were obtained from Pharmacia Fine Chemicals, Inc., Piscataway, N. J. DE52 cellulose was obtained from Whatman. Hexadimethrene bromide (Polybrene) was obtained from Abbott Laboratories, North Chicago, Ill.

Antisera. Antibodies prepared in rabbits against human plasma proteins, anti- $\alpha_{2}$-macroglobulin $\left(\alpha_{2}-\mathrm{M}\right)$, anti-Cî-inactivator, and anti- $\alpha_{1}$-antitrypsin $\left(\alpha_{1}-\mathrm{AT}\right)$ were purchased from Behringwerke AG, Marburg-Lahn, West Germany.

Plasma samples. To obtain human, monkey, rabbit, rat, goat, and dog plasma, nine vol of blood from healthy donors was drawn directly into plastic tubes containing 1 vol of $3.8 \%$ citrate and was immediately centrifuged at $2,500 \mathrm{~g}$ at $4^{\circ} \mathrm{C}$ to remove the cells. Plasma was then stored at $-70^{\circ} \mathrm{C}$. For certain experiments, hexadimethrene bromide was added to the citrate to produce a final concentration of $50 \mu \mathrm{g} / \mathrm{ml}$ plasma. Factor XII-deficient plasma was obtained from a donor with congenital deficiency of factor XII. Fletcher factor-deficient plasma, which lacks functional and immunochemical kallikrein (9), from a single donor was a gift from Dr. C Abilgaard, University of California at Davis. Plasma samples were obtained from patients included in a previous study (10) measuring functional kallikrein and bradykinin. The criteria for diagnosis have been described (10). Patients with prothrombin times more than $3 \mathrm{~s}$ from control were considered to have severe disease; those with normal prothrombin times, mild disease.

Protein determination. Protein was determined by absorbance at $280 \mathrm{~nm}$ with $E_{280}{ }^{1 \%}$ assumed equal to 10 . In some cases the method of Groves, David, and Sells (11) or Lowry, Rosebrough, Farr, and Randall (12) was used.

Determination of kallikrein and kinin levels. Kallikrein activity was measured either by its arginine esterase activity or by its proteolytic activity. Esterase activity was measured with TAMe by a modification of the method of Siegelman, Carlsen, and Robertsen (13), which has been described in detail (14). The proteolytic activity of kallikrein was measured by its ability to release bradykinin from plasma containing $3 \mathrm{mM}$ o-phenanthroline. Kinins were measured by the radioimmunoassay technique (15).

Further purification of plasma kallikrein. Human kallikrein as prepared according to the procedure of Colman, Mattler, and Sherry (8) was further purified in an attempt to remove the only major contaminant, gamma globulin, by gel filtration on Sephadex G-200, as described in Fig. 1. The purified preparation was further characterized by polyacrylamide gel electrophoresis (7\%), performed according

${ }^{1}$ Abbreviations used in this paper: $\alpha_{1}-\mathrm{AT}, \alpha_{1}$-antitrypsin; $\alpha_{2}-\mathrm{M}, \alpha_{2}$-macroglobulin; PKA, low molecular weight prekallikrein activators; TAMe, L-tosyl arginine methyl ester.

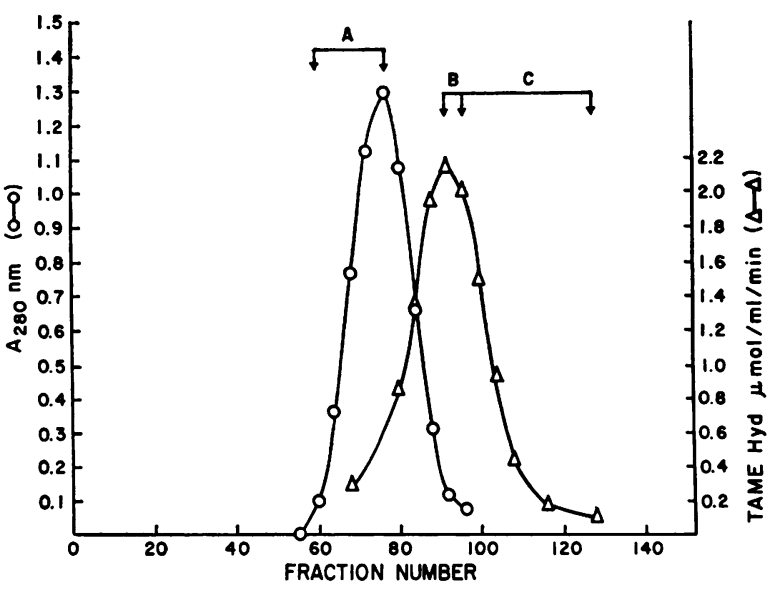

FIGURE 1 Gel filtration of partially purified kallikrein. Starting material was $32.4 \mathrm{mg}$ of the second carboxymethyl Sephadex chromatography of kallikrein (8). The specific activity of the kallikrein was $9.3 \mu \mathrm{mol}$ TAMe hydrolyzed/ $\mathrm{ml} / \mathrm{min}$. A $2.0 \times 97-\mathrm{cm}$ column was packed with Sephadex G-200 and equilibrated with $0.016 \mathrm{M}$ sodium phosphate, $\mathrm{pH} 8.0$, in $0.13 \mathrm{M} \mathrm{NaCl}$. Fractions of $1.3 \mathrm{ml}$ were collected. The flow rate was $15 \mathrm{ml} / \mathrm{h}$ at $4^{\circ} \mathrm{C}$ in a downward direction. Circles denote the absorption at $280 \mathrm{~nm}$ while the triangles represent the esterase activity. Pools $\mathrm{A}, \mathrm{B}$, and $\mathrm{C}$ include the fractions denoted on the graph.

to Davis (16), as described earlier (4). Duplicate gels were run. One gel was stained and the other was sliced in $2-\mathrm{mm}$ segments and eluted overnight at $4^{\circ} \mathrm{C}$ with $5 \mathrm{mM}$ potassium phosphate in $0.15 \mathrm{M} \mathrm{NaCl}$ containing $10^{-3} \mathrm{M} \mathrm{KCN}, \mathrm{pH} 8.0$.

Preparation of activators of prekallikrein. These enzymes were obtained in a partially purified state as a byproduct of kallikrein preparation and further purified as described earlier (4). Large activator was a single band on analytical polyacrylamide electrophoresis while low molecular weight prekallikrein activators (PKA) was comprised of several bands in the prealbumin region, which all had activator activity.

Preparation of Hageman factor. Factor XII was purified according to the procedure of Cochrane and Wuepper (3) and further eluted off the acrylamide gels (4).

Preparation and assay of gamma globulins. Gamma globulins were by-products of the final step of the kallikrein purification. They were present in the front of the first peak (pool A, Fig. 1). Gamma globulin was measured with radial immunodiffusion plates (Behring Diagnostics, Inc., Woodbury, N. Y.).

Isolation of inhibitors of kallikrein from plasma. To separate $\mathrm{C} \overline{1}$ inactivator, $\alpha_{2}-\mathrm{M}$, and $\alpha_{1}-\mathrm{AT}$ from each other, the gel filtration procedure of McConnell (17) was used with some modification, as detailed in Fig. 8. Eluted fractions were tested for the kallikrein inhibitors by the arginine esterase assay. For this purpose, $0.03 \mathrm{ml}$ purified kallikrein sample $(9.3 \mu \mathrm{mol}$ TAMe hydrolyzed/ml) was incubated with $0.5 \mathrm{ml}$ of the fractions for $5 \mathrm{~min}$ at $25^{\circ} \mathrm{C}$ and esterase activity of the mixtures was determined. Fractions were also checked for prekallikrein, with PKA as activator. For this purpose, $0.03 \mathrm{ml}$ PKA was incubated with $0.2 \mathrm{ml}$ of each fraction for $60 \mathrm{~S}$ at $25^{\circ} \mathrm{C}$. The kallikrein formed was then measured by the TAMe assay.

Antibody production. Purified kallikrein obtained after 
gel filtration (pool C, Fig. 1) was mixed with equal volume of complete Freunds' adjuvant and injected in the toe pads of three young Australian white rabbits. The rabbits received $30 \mu \mathrm{g}$ (in $0.075 \mathrm{ml}$ ), $50 \mu \mathrm{g}$ (in $0.125 \mathrm{ml}$ ), and 150 $\mu \mathrm{g}$ (in $0.375 \mathrm{ml}$ ), respectively. After 2 wk the rabbits received as a booster dose, the same amounts of kallikrein subcutaneously injected in the neck area. After a week, blood samples were drawn from the rabbits and incubated at $37^{\circ} \mathrm{C}$ for $3 \mathrm{~h}$ and at $4^{\circ} \mathrm{C}$ for $18 \mathrm{~h}$ before separating the serum by centrifugation at $2,500 \mathrm{~g}$. Complement was inactivated by heating the serum at $56^{\circ} \mathrm{C}$ for $30 \mathrm{~min}$. Additional booster doses were given at 7-10 day intervals. No antibody was detected in rabbit receiving $30 \mu \mathrm{g}$. All experiments were performed with the antiserum from the other two rabbits, which gave equivalent results.

Removal of anti-IgG from rabbit antisera. Two different approaches were employed to absorb the anti-IgG found after injection of kallikrein into rabbits. In one, $0.05 \mathrm{ml}$ of Fletcher factor-deficient human plasma was added to $5 \mathrm{ml}$ of antiserum and the mixture was incubated at $37^{\circ} \mathrm{C}$ for $1 \mathrm{~h}$ and then left at $4^{\circ} \mathrm{C}$ for $3 \mathrm{~h}$. The heavy precipitate formed was removed by centrifugation at $3,000 \mathrm{~g}$ at $4^{\circ} \mathrm{C}$. Addition of larger amounts of the plasma failed to produce further precipitation. In the second, $0.1 \mathrm{ml}$ purified IgG containing $600 \mu \mathrm{g}$ protein, obtained from the gel filtration of kallikrein sample on Sephadex G-200 (Fig. 1, pool A), was added to $2 \mathrm{ml}$ antisera. Incubation and centrifugation were carried out as above.

Immunoelectrophoresis. Immunoelectrophoresis was carried out in the universal electrophoresis cell (Buchler Instruments Div., Nuclear Chicago Corp., Fort Lee, N. J.) by the method of Scheidegger (18). On each microscopic slide $(2.5 \times 7.5 \mathrm{~cm}), 3.6 \mathrm{ml}$ of $1 \%$ agar gel in $0.04 \mathrm{M}$ barbital buffer at $\mathrm{pH} 8.6$ was placed and let stand at room temperature, overnight storage at $4^{\circ} \mathrm{C}$. After boring the wells in the gels, small volumes of antigen samples were applied with a micro syringe, or plastic micro syringe in case of plasma samples in wells. To apply sufficient antigen, a $7-\mu \mathrm{l}$ volume was placed in the antigen well. Just before the volume was adsorbed, another 7- $\mu 1$ volume was added, and this was repeated until $20 \mu 1$ total volume had been placed in the well. Electrophoresis carried out for $3 \mathrm{~h}$ at $6 \mathrm{mamp} / \mathrm{plate}$. After completion of the electrophoresis, a groove $2 \mathrm{~mm}$ wide was made in the center of the plate. The antibody $(0.15 \mathrm{ml})$ was then placed in the groove and the plate was left overnight at room temperature. To stain the plates, they were first soaked in saline for 6 days with frequent change of the saline solution to completely remove the nonprecipitated proteins. Then the plates were stained with $0.25 \%$ Coomassie brilliant blue for $1 \mathrm{~h}$ and destained with a mixture of $10 \%$ of isopropyl alcohol and $10 \%$ of acetic acid.

Immunodiffusion. Double diffusion was performed by the method of Ouchterlony (19) with prepared plates (Pentex Biochemical, Kankakee, Ill.) containing $1 \%$ agarose in 0.1 $\mathrm{M}$ borate in $0.15 \mathrm{M} \mathrm{NaCl}, \mathrm{pH}$ 8.1.

Radial immunodiffusion. The general procedure was that of Mancini, Carbonaro, and Heremans (20). Diffusion plates were made with 6 vol of $1.5 \%$ agarose, 1 vol of absorbed antisera, and 1 vol of barbital buffer, $\mathrm{pH} 7.6$, containing merthiolate to give a final concentration of $0.01 \%$. On each diffusion dish, $3.6 \mathrm{ml}$ of the mixture was placed and left to stand overnight in a moist chamber of $4^{\circ} \mathrm{C}$. Wells with $2.25 \mathrm{~mm}$ diameter were then bored in the gel. Varying volumes from 5 to $15 \mu 1$ were placed in the wells and the reaction recorded at $18 \mathrm{~h}$ and $48 \mathrm{~h}$. No difference in the diameter of the precipitin rings were found after $18 \mathrm{~h}$.

Studies on the interaction of kallikrein or prekallikrein with different plasma inhibitors. A mixture of $0.02 \mathrm{ml}$ of normal plasma and $0.02 \mathrm{ml}$ of purified kallikrein, containing 6-8 $\mu \mathrm{g}$ kallikrein, was incubated for $5 \mathrm{~min}$ at $25^{\circ} \mathrm{C}$. In the case of studies with isolated plasma inhibitors of kallikrein, $0.02 \mathrm{ml}$ of kallikrein was incubated with $0.015 \mathrm{ml}$ of each inhibitor separately for a period of 5 and $30 \mathrm{~min}$ at $25^{\circ} \mathrm{C}$. The reaction was terminated by the addition of $0.005 \mathrm{ml}$ of 0.1 TAMe solution to the mixture, and $0.02 \mathrm{ml}$ of the mixture was then placed in each of the wells made in $1 \%$ agar plates. In the other well was $0.02 \mathrm{ml}$ of the plasmasaline or kallikrein saline mixture. Electrophoresis of the immunoplates was carried out at room temperature for $3 \mathrm{~h}$ at $6 \mathrm{mamp} /$ plate. After the run, the center groove was filled with $0.15-0.20 \mathrm{ml}$ of the antiserum against kallikrein or antiserum against kallikrein inhibitors, such as $\mathrm{C}^{-1}$ inhibitor, $\alpha_{2}-\mathrm{M}$, and $\alpha_{1}-\mathrm{AT}$. Precipitin arcs were developed overnight at room temperature in a moist chamber.

Statistical analysis of the data obtained on the kallikrein levels in normal and cirrhotic patients. The kallikrein antigen levels in normals and cirrhotic patients were plotted against prekallikrein activities and a regression line was calculated by the method of least squares. The $95 \%$ confidence limits were calculated by a standard formula (21).

\section{RESULTS}

\section{Purification of human kallikrein}

After filtration through the Sephadex G-200 column (Fig. 1), the esterase activity (peak fraction 92) eluted after the protein peak (peak fraction 76), but some overlaps occur. The first protein peak had an estimated mol wt of 160,000 and was shown to contain over $95 \%$ gamma globulin by radial immunodiffusion. Three pools were made, $A, B$, and $C$, as indicated in the figure. The specific activity of kallikrein in tube 92 was 24 and the maximum specific activity in tubes comprising pool $\mathrm{C}$ was estimated at 40 . Pools $\mathrm{B}$ and $\mathrm{C}$, both in the region of the esterase peak, revealed 35 and $8 \%$ gamma globulin, and the specific activities of arginine esterase after concentration were 9.3 and $10 \mu \mathrm{mol}$ TAMe hydrolyzed/ $\mathrm{min} / \mathrm{ml}$, respectively. The loss of activity was probably due to surface denaturation during concentration, since the addition of bovine serum albumin before concentration increased the activity in the concentrate three-tofourfold.

Purified kallikrein (pool C) was run in acrylamide gels in duplicate (Fig. 2). One gel was stained and a major protein band segment, $4-5$, and a minor band segment, 7, were found. The replicate gel, when sliced and eluted, was tested for hydrolysis of TAMe, the formation of kinin from normal plasma, and kallikrein antigen. All three activities were present in segment 4 and 5. A smaller amount of esterase activity was present in later segments but no kinin or kallikrein were present. 

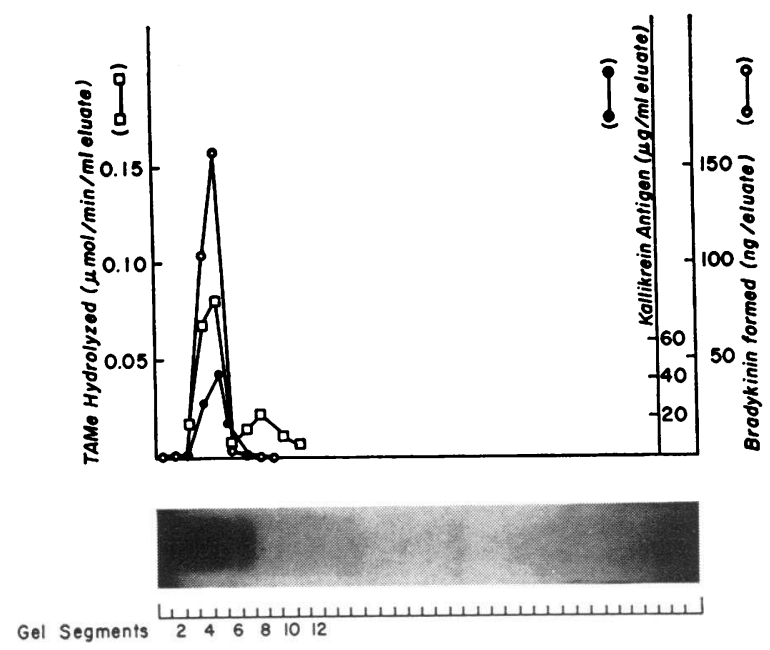

Figure 2 Disk gel electrophoresis of the G-200 Sephadex fraction of kallikrein peak pool C. Electrophoresis was preformed with $100 \mu \mathrm{g}$ of protein, as described in Methods. The TAMe esterase activity eluted from each $6.2-\mathrm{mm}$ segment is plotted.

\section{Antiserum to human kallikrein}

Plasma containing hexadimethrene to prevent activation of factor XII and subsequent conversion of prekallikrein to kallikrein was subjected to immunoelectrophoresis on the same gel as purified kallikrein (pool C, Fig. 1). When developed with antiserum, two identical lines were observed (Fig. 3A) with both plasma and kallikrein. The arc closer to the antigen well appears to be the major component in the purified kallikrein preparation, and enriched compared to plasma. The antiserum was then adsorbed with Fletcher factor-deficient plasma (which lacks functional and antigenic prekallikrein) or adsorbed with purified IgG. Both of the adsorbed antisera failed to react with IgG but gave a single arc with kallikrein (Fig. 3, B and C). The single arc corresponding to the major component of kallikrein was nearer the antigen well (Fig. 3A).

The specificity of the kallikrein antibody is further confirmed by the Ouchterlony diffusion technique. Both Fletcher factor-adsorbed antibody and IgG-adsorbed antibody show a single line with a reaction of identity with kallikrein.

\section{Species specificity of the kallikrein antibody}

After removal of the contaminating anti-IgG from rabbit antiserum, the absorbed antiserum was tested against plasmas from animals as well as from humans. Only human and monkey plasmas reacted against the antibody.

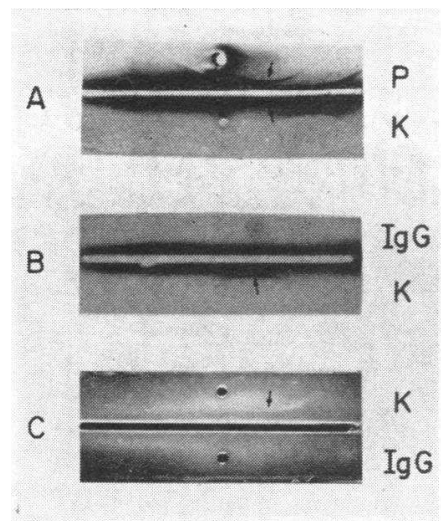

FIgURE 3 Immunoelectrophoresis of kallikrein and gamma globulin against antisera directed to kallikrein. The plasma (P) used contained $50 \mu \mathrm{g} / \mathrm{ml}$ hexadimethrine. The gamma globulin (IgG) is obtained from pool A of Fig. 1. The kallikrein designated $\mathrm{K}$ is concentrated from pool $\mathrm{C}$ and $20 \mu \mathrm{l}$ containing $8 \mu \mathrm{g}$ was used. Plate A: unadsorbed antiserum. Plate B: antibody adsorbed with Fletcher factordeficient plasma. Plate $\mathrm{C}$ : antibody adsorbed with purified IgG.

\section{Distribution of kallikrein antigen}

As expected, the kallikrein antigen at different stages of the purification reacted with the antibody (Fig. 4), and they showed complete identity with each other.

Precipitation of kallikrein by kallikrein antibody

When the absorbed antiserum directed against kallikrein was incubated with kallikrein at $37^{\circ} \mathrm{C}$ for $1 \mathrm{~h}$, a

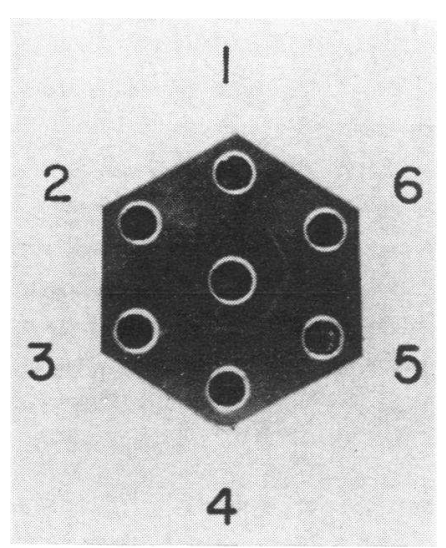

FIGURE 4 Immunodiffusion of kallikrein at various stages of purification. The antibody in the center well is $35 \mu \mathrm{l}$ of antibody adsorbed with Fletcher factor-deficient plasma. Similar results were obtained with gamma globulin-adsorbed antibody. The antigens were put in the outside wells at concentrations of $0.5-2.0 \mathrm{mg} / \mathrm{ml}$, except for plasma. 1 , human plasma; 2, ceruloplasmin-containing preparation (8); 3 , carboxymethyl Sephadex chromatography peak $1 ; 4$, excluded peak from DEAE cellulose chromatography. 5, second carboxymethyl cellulose chromatography; 6, G-200, peak C, Fig. 1.

Immunochemical Studies of Plasma Kallikrein 
heavy precipitate was formed. After removal of immunoprecipitate, the supernate showed no cross-reaction when run against kallikrein in an Ouchterlony diffusion plate.

\section{Effect of the kallikrein antibody on kallikrein activity}

Table I summarized the inhibition of kallikrein activity by antisera when the esterase activity of kallikrein is measured. A maximum of $53.5 \%$ inhibition of kallikrein was obtained when $0.03 \mathrm{ml}$ of the antisera was incubated with $0.02 \mathrm{ml}$ kallikrein ( $2 \mu \mathrm{mol}$ TAMe hydrolyzed $/ \mathrm{ml} / \mathrm{min}$ ) for $90 \mathrm{~s}$ at $25^{\circ} \mathrm{C}$ (Table I). Under the same conditions, the normal serum caused $25.5 \%$ inhibition. When the bradykinin release by kallikrein was measured, the rabbit antisera caused almost complete inhibition $(91.5 \%)$ of kallikrein activity, while under the same conditions, normal rabbit sera caused $20.7 \%$ inhibition (Table I).

\section{Effect of antiserum on the activation of prekallikrein}

Esterase assay. At an antiserum-to-plasma ratio of 0.2 and incubation time of $60 \mathrm{~s}$ at $25^{\circ} \mathrm{C}$, using PKA as an activator resulted in $50 \%$ inhibition with the antisera (Table II). At the same ratio, large activator in-

TABLE I

Inhibition of Kallikrein Activity by Antiserum

\begin{tabular}{|c|c|c|c|c|c|}
\hline \multirow{3}{*}{$\begin{array}{l}\text { Incubation of } \\
\text { kallikrein } \\
\text { with } \\
\text { antiserum }\end{array}$} & \multicolumn{5}{|c|}{ Inhibition } \\
\hline & \multicolumn{2}{|c|}{ Esterase activity* } & & \multicolumn{2}{|c|}{ Bradykinin release } \\
\hline & RNS & RAS & & RNS & RAS \\
\hline$s$ & & & $\%$ & & \\
\hline 30 & 28 & 41.5 & & - & - \\
\hline 60 & 26.5 & 47.5 & & - & - \\
\hline 90 & 25.5 & 53.5 & & 20.7 & 91.5 \\
\hline
\end{tabular}

RAS, rabbit antiserum; RNS, rabbit normal serum.

* Esterase inhibition of kallikrein was carried out by incubation of $0.03 \mathrm{ml}$ of RAS or RNS (decomplemented and adsorbed with Fletcher factor-deficient plasma) and $10 \mu \mathrm{g}$ of purified kallikrein in $0.02 \mathrm{ml}$ volume for periods up to $90 \mathrm{~s}$ at $25^{\circ} \mathrm{C}$. The reaction was stopped by the addition of ice-cold TAMe, followed by the determination of the TAMe hydrolyzed. In all studies, heat-inactivated serum from unimmunized rabbits was used as a control.

$\ddagger$ Inhibition of the proteolytic activity of kallikrein by the RAS or RNS was performed by incubation of $0.02 \mathrm{ml}$ of purified kallikrein with $0.005 \mathrm{ml}$ of the serum at $25^{\circ} \mathrm{C}$ for $90 \mathrm{~s}$, followed by the addition of $0.20 \mathrm{ml}$ of heated plasma $\left(61^{\circ} \mathrm{C} 2 \mathrm{~h}\right)$ containing $3 \mathrm{mM}$ o-phenanthroline. The mixture was further incubated for $4 \mathrm{~min}$ and the reaction stopped by the addition of $0.03 \mathrm{ml}$ of $20 \%$ trichloroacetic acid. The levels of the bradykinin were measured by the radioimmunoassay. hibits to a similar degree (59\%). In contrast, with factor $\mathrm{XII}_{\mathbf{A}} 75 \%$ inhibition is observed, essentially the same as when kaolin was used to activate prekallikrein ( $86 \%)$. Inhibition with unimmunized normal rabbit sera ranged from 0 to $16 \%$.

Bradykinin assay. Kinin release measurement confirms the pattern of inhibition with different activators. When PKA or large activator was used as an activator, about $24 \%$ inhibition of prekallikrein occurred. In the case of factor $\mathrm{XII}_{\mathrm{A}}$, a higher inhibition of $67 \%$ was found, similar to that seen with kaolin (54\%). The inhibition by antiserum displays a definite concentration dependence, as seen for PKA and kaolin. However, in keeping with the weaker inhibition toward PKA, an antiserum/plasma ratio of 0.5 was required to obtain $95 \%$ inhibition, compared to a ratio of 0.3 for kaolin. In these experiments, $850 \mathrm{ng} / \mathrm{ml} \mathrm{kinin} \mathrm{was} \mathrm{re-}$ leased in the absence of the antisera. Normal rabbit sera used instead of antisera, as a control, had no inhibitory effect. In contrast, it enhanced the bradykinin levels, probably because of kininogen in the sera ( $\mathrm{Ta}$ ble II).

Interaction between kallikrein and inhibitors in plasma

Incubation of purified kallikrein with plasma resulted in formation of a new precipitin arc, demonstrated by the immunoelectrophoresis with antiserum against kallikrein (Fig. 5). In contrast to kallikrein alone or prekallikrein (in plasma), which at $\mathrm{pH} 8.6$ migrate toward the negative pole in the electrical field, the product of the interaction between enzyme and inhibitor remained at the origin. Attempts to identify the inhibitor responsible for this component were made with specific antibodies for each inhibitor. In the absence of kallikrein, $\mathrm{C} \overrightarrow{1}$ inactivator migrated a very short distance toward the positive pole, while $\alpha_{1}-\mathrm{AT}$ had the greatest migration and $\alpha_{2}-\mathrm{M}$, intermediate. After incubation of plasma and purified kallikrein, no change in migration or intensity of the precipitin arcs was evident.

\section{Partial purification of kallikrein inhibitors}

Gel filtration of normal plasma through Sephadex G-200 resolved the kallikrein inhibitor activities into three completely separate peaks, similar to those obtained by McConnell (17). The inhibitor activity peak eluting first (peak 1) is $\alpha_{2}-\mathrm{M}$, peak 2 is $\mathrm{C} \overline{1}$ inactivator, and peak 3 is $\alpha_{1}$-AT (Fig. 6). The prekallikrein activity was located in the area of the $C \overline{1}$ inactivator peak. The fraction containing inhibitors were pooled separately, as indicated in the graph, and concentrated to yield an absorbance at $280 \mathrm{~nm}$ of about $27 / \mathrm{ml}$. The concentrated samples contained approximately twice the amount of the inhibitor present in the original plasma. In the case 
TABLE II

Inhibition of Prekallikrein Activation by Antiserum to Prekallikrein

\begin{tabular}{|c|c|c|c|c|c|c|}
\hline \multirow{3}{*}{$\begin{array}{l}\text { Prekallikrein } \\
\text { activator } \\
\text { used }\end{array}$} & \multirow{3}{*}{$\begin{array}{l}\text { Activator } \\
\text { in mixture }\end{array}$} & \multirow{3}{*}{$\begin{array}{c}\text { Antiserum- } \\
\text { to-plasma } \\
\text { ratio }\end{array}$} & \multicolumn{4}{|c|}{ Inhibition determined } \\
\hline & & & \multicolumn{2}{|c|}{ Esterase assay* } & \multicolumn{2}{|c|}{ Bradykinin assay $\ddagger$} \\
\hline & & & RNS & RAS & RNS & RAS \\
\hline & $U / m l$ & vol/vol & & & & \\
\hline \multirow[t]{3}{*}{ PKA } & 4.3 & 0.2 & 7.5 & 50 & 0 & 24 \\
\hline & & 0.4 & 一 & 一 & 0 & 87.7 \\
\hline & & 0.5 & - & - & - & 95.8 \\
\hline Large activator & 4.0 & 0.2 & 16.0 & 59 & - & 23 \\
\hline $\mathrm{F} \mathrm{XII} A$ & 3.0 & 0.2 & 14 & 75 & - & 67 \\
\hline \multirow[t]{2}{*}{ Kaolin } & $5 \mathrm{mg}$ & 0.2 & 0 & 86.0 & 0 & 54.2 \\
\hline & & 0.3 & - & - & - & 95.0 \\
\hline
\end{tabular}

RAS, rabbit antiserum; RNS, rabbit normal serum.

* Measurement of arginine esterase activity was carried out by the incubation of $0.20 \mathrm{ml}$ of normal plasma with $0.04 \mathrm{ml}$ of either RNS or RAS for $5 \mathrm{~min}$ at $25^{\circ} \mathrm{C}$. The activation of prekallikrein was then carried out by the addition of an equal volume of $10 \mathrm{mg} / \mathrm{ml} \mathrm{kaolin}$ in $0.1 \mathrm{M}$ phosphate buffer containing $0.13 \mathrm{M} \mathrm{NaCl}$ at $\mathrm{pH} 7.65$ or by the addition of $0.2 \mathrm{ml}$ of PKA, large activator, or active factor XII. After addition of the activator, the mixture was incubated for exactly $60 \mathrm{~s}$ at $25^{\circ} \mathrm{C}$ and the reaction was then stopped by the addition of ice-cold TAMe. The amount of TAMe hydrolyzed was then determined.

$\ddagger$ Kinin release was performed by the incubation of $0.25 \mathrm{ml}$ of normal plasma containing $3 \mathrm{mM}$ o-phenanthroline with up to $0.10 \mathrm{ml}$ of decomplemented and absorbed RAS or RNS. The mixture was preincubated for $5 \mathrm{~min}$ at $25^{\circ} \mathrm{C}$, then an equal volume of $10 \mathrm{mg} / \mathrm{ml}$ kaolin was added to it and further incubated for exactly $60 \mathrm{~s}$ at $25^{\circ} \mathrm{C}$. Similar studies were carried out by substitution of PKA, large activator, and active factor XII for kaolin, but after addition of the activator the mixture was incubated for $2 \mathrm{~min}$ at $25^{\circ} \mathrm{C}$. The reaction was terminated by the addition of $0.05 \mathrm{ml}$ of $20 \%$ trichloroacetic acid/ $\mathrm{ml}$ of the mixture. The level of kinin formed was then determined by the radioimmunoassay.

of $\bar{C} \overline{1}$ inactivator, only the second half of the peak fractions 49-54) were pooled to avoid contamination with prekallikrein. Each of the separated inhibitors after concentration formed a single precipitin line only against its respective antisera when tested in the diffusion plates. Only $\alpha_{2}-\mathrm{M}$ showed a trace contamination with $\mathrm{C} \overline{1}$ inactivator.

\section{Interaction between kallikrein and partially purified inhibitors}

Partially purified plasma inhibitors obtained by gel filtration were separately incubated with purified kallikrein. Immunoelectrophoresis developed with antikallikrein antiserum revealed physical interaction between kallikrein and $\mathrm{C}^{\overline{1}}$ inactivator (Fig. 7 ) as evidenced by appearance of a new precipitin arc. No new component was evident with $\alpha_{1}$-AT or $\alpha_{2}-\mathrm{M}$ (Fig. 7). A marked decrease in the apparent concentration of kallikrein was noted after incubation with partially purified $\alpha_{2}-\mathrm{M}$, but no new arc was noted. Similar precipitin arcs were obtained whether kallikrein was incubated with the in-
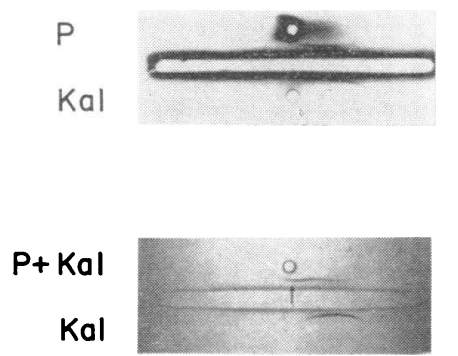

FIGURE 5 Immunoelectrophoresis of the interaction of kallikrein with kallikrein inhibitors in plasma. Samples of 20 $\mu \mathrm{l}$ were applied in the wells of $1 \%$ agar plates and electrophoresis was run as described in the Methods. Plates were developed with antisera against kallikrein adsorbed with Fletcher factor-deficient plasma. Kal denotes kallikrein. Plasma (P) sample has been concentrated twofold. Plates were stained with Coomassie blue. Arrow indicates new precipitin arc. 


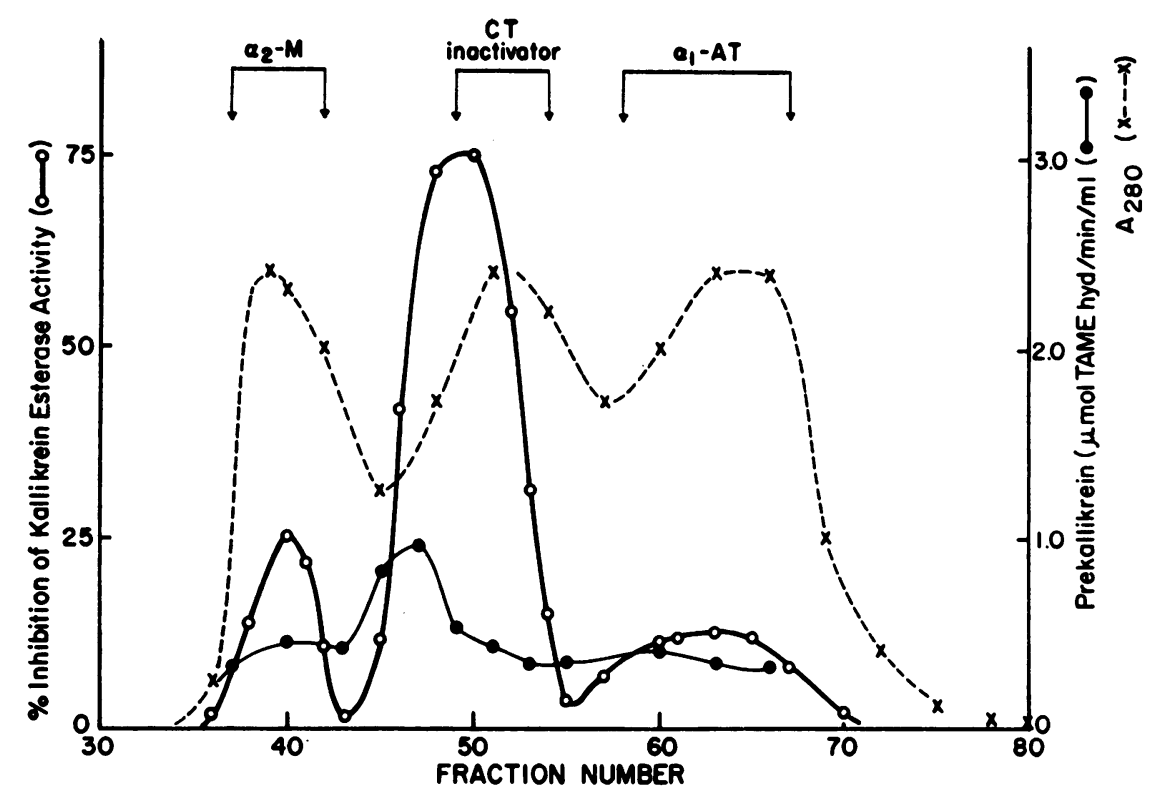

FIGURE 6 Gel filtration of normal plasma to separate kallikrein inhibitors. A $2 \times 100-\mathrm{cm}$ siliconized glass column was packed with G-200 Sephadex and equilibrated with $0.016 \mathrm{M}$ sodium phosphate, $\mathrm{pH} 8.0$, in $0.13 \mathrm{M} \mathrm{NaCl}$. Plasma from a healthy fasting individual dialyzed against the same buffer was applied onto the column and $3.1-\mathrm{ml}$ fractions were collected with flow rate of $17 \mathrm{ml} / \mathrm{h}$. Arrows indicate fractions pooled for each inhibitor.

libitors for 5 or $30 \mathrm{~min}$. In contrast, using antisera against each of the inhibitors failed to make any difference in either migration or concentration.

\section{Immunochemical estimation of kallikrein levels} in plasma

Different amounts of purified kallikrein were reacted against absorbed antiserum in radial immunodiffusion plates. A linear relationship between antigen concentration and the square of the diameter of the precipitin rings was found (Fig. 8). This standard curve was used to estimate the levels of kallikrein in the normal and patients' plasmas. With an antibody adsorbed with IgG, Fletcher factor-deficient plasma demonstrated no detectable kallikrein by radial immunodiffusion.

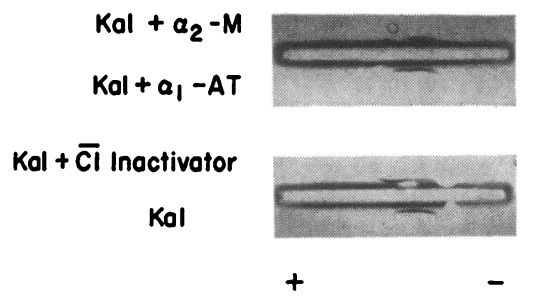

FIGURE 7 Interaction of isolated inhibitors with kallikrein. Samples in a total volume of $0.02 \mathrm{ml}$ were applied in the wells of $1 \%$ agar plates and electrophoresis carried out as described. Plates were developed with antiserum against kallikrein absorbed with Fletcher factor-deficient plasma.

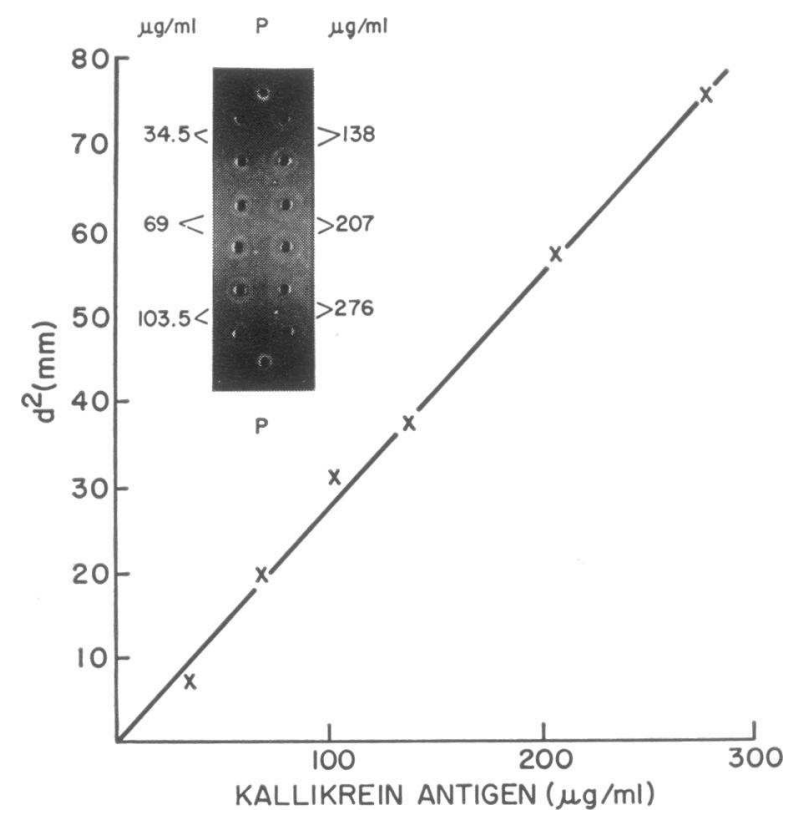

FIgURE 8 Radial immunodiffusion assay of prekallikrein. The insert shows the actual rings of the radial immunodiffusion. The plate was prepared as described in Methods. The antibody was adsorbed with IgG. Kallikrein at a concentration of $150 \mu \mathrm{g} / \mathrm{ml}$ was used. The concentration of kallikrein used in duplicate is indicated near the inset. The two wells marked "P" contain $10 \mu \mathrm{l}$ of two normal plasma samples. The kallikrein antigen concentrations are based on a volume of $0.01 \mathrm{ml}$ of sample. 
Immunochemical estimation of kallikrein in plasma of patients with alcoholic cirrhosis

The 19 normal individual plasmas showed a functional kallikrein activity level of $98 \pm 11 \mathrm{SD} \mu \mathrm{mol}$ TAMe hydrolyzed $/ \mathrm{ml} / \mathrm{h}$ which compares with $97 \pm 24$ reported previously (6), while the kallikrein antigen had a mean of $103 \pm 13 \mu \mathrm{g} / \mathrm{ml}$. Nine patients with mild alcoholic cirrhosis had a mean prekallikrein activity of $48 \pm 12 \mu \mathrm{mol} / \mathrm{ml} / \mathrm{h}$ and a mean prekallikrein antigen of $50 \pm 8$. In 11 patients with severe cirrhosis, the mean prekallikrein activity was $8 \pm 9$ and the mean antigen was $39 \pm 11$ (Fig. 9).

The correlation coefficient for normal subjects was $r=0.87(P<0.001)$ and for mild cirrhosis $r=0.80$ $(P<0.01)$, indicating a highly probable relationship between prekallikrein antigen and activity. The slopes of the regression lines for these two groups and the intercepts do not differ significantly $(P>0.30)$ and all of the values of the mild cirrhosis lie within the $95 \%$ confidence limits of the normal regression line. In contrast, the correlation coefficient for the severe cirrhotics was $r=0.06(P>0.80)$, indicating that the antigen and functional activity of prekallikrein are independent of each other in this group. Furthermore, 5 of 11 of these patient values lie above the regression line for normal.

\section{DISCUSSION}

Purification of human plasma kallikrein has been a challenging problem, because of the close resemblance of kallikrein to other plasma proteases and to $\boldsymbol{\gamma}$-globulin. Harpel (22) was unable to separate the kallikrein from factor XI by isoelectric focusing, acrylamide gel electrophoresis, or G-200 Sephadex. Schreiber, Kaplan, and Austen (23) found that the isoelectric points of kallikrein, plasminogen proactivator, and factor XI are a few tenths $\mathrm{pH}$ apart and a kallikrein preparation demonstrated a broad band from $\mathrm{pH} 7.5$ to 8.9 after focusing (24). Prekallikrein purified by Kaplan, Kay, and Austen (24) contained IgG as detected by radial immunodiffusion. Similar problems have been encountered in this laboratory. When highly purified plasma kallikrein was prepared (8) and subjected to acrylamide gel electrophoresis, one broad band was found. The properties of the kallikrein in this preparation agreed with those found by other workers. The enzyme has a molecular weight of approximately 100,000 (8), migrates electrophoretically as gamma globulin, releases kinin from heated plasma $\left(61^{\circ} \mathrm{C}\right.$ for $\left.2 \mathrm{~h}\right)$, displays arginine esterase activity, and is inhibited by soybean trypsin inhibitor, diisopropylphosphofluoridate, $\mathrm{C} 1$ esterase inhibitor, and $\alpha_{2}-\mathrm{M}$. However, gamma globulin was later detected in the kallikrein I preparation, although no $\mathrm{C} \overline{1}$ esterase, thrombin, plasmin, plasminogen, or clotting

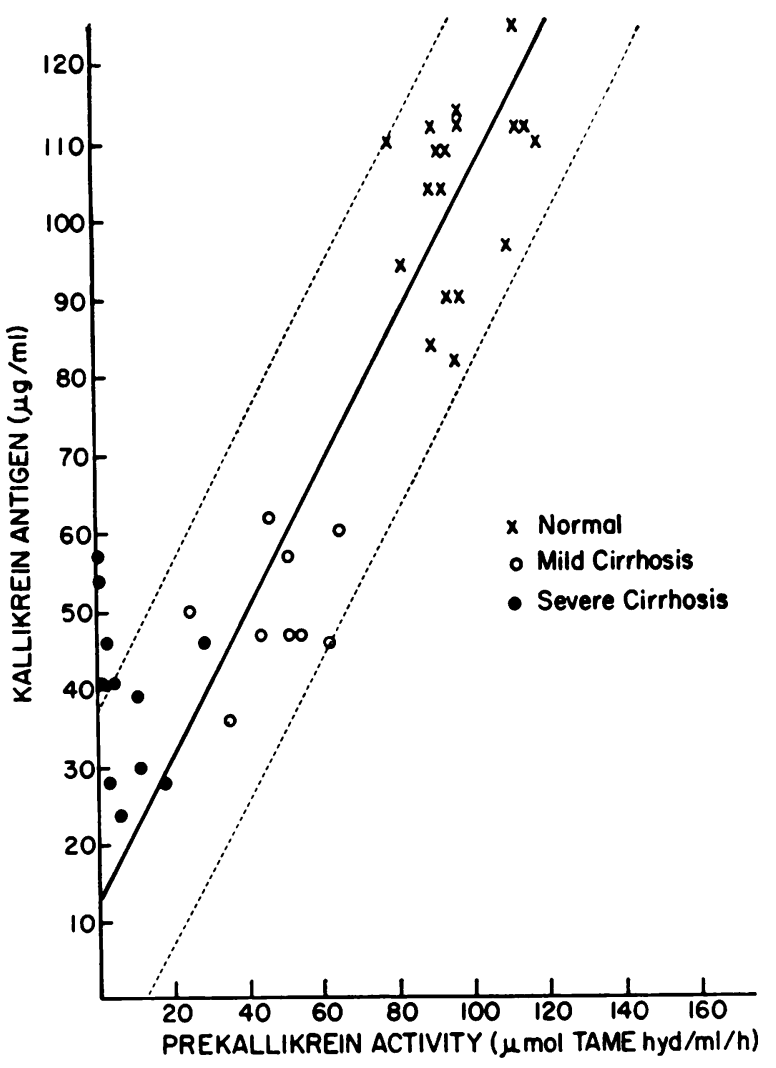

FIGURE 9 The relationship of prekallikrein activity to prekallikrein antigen. The solid line is the regression line for normal individuals. The equation for the line is $y=12.6$ $+0.93 x$. The dashed lines are $95 \%$ confidence limits. The equation for the regression line of the patients with mild cirrhosis is $y=13.4+0.73 x$ and for severe cirrhosis $y=$ $35.4+0.1 x$.

factors I to XII could be demonstrated in the preparation (8). Attempts at immunization with kallikrein I yielded only antibodies against IgG. Starting with this partially purified preparation, gel filtration on G-200 Sephadex resulted in a kallikrein preparation that contained only $8 \%$ gamma globulin. Kallikrein on the disk gel electrophoresis yielded one major protein band with esterase, kinin liberating activity, and kallikrein antigen.

Kallikrein preparations after gel filtration elicited only antibodies against kallikrein and IgG. After adsorption with IgG, a single antigenic component was visualized in the purified kallikrein preparation by immunoelectrophoresis and immunodiffusion. Nevertheless, the possibility was considered that this antigenic component represents an additional protein, not kallikrein. Wuepper (9) has shown that a congenital coagulation disorder known as Fletcher factor deficiency is due to a lack of prekallikrein, as measured functionally and immunologically. After adsorption of the antibody preparation with Fletcher factor-deficient plasma, a single pre- 
cipitin arc identical to that demonstrated with the antibody adsorbed with gamma globulin was observed. The observation suggests that the only other major component in the kallikrein preparation was gamma globulin and that the remaining antibody after either adsorption was directed against kallikrein.

The adsorbed kallikrein antibody was then examined to see if it could detect prekallikrein in plasma. By immunoelectrophoresis, identical migration was found for purified kallikrein and prekallikrein in plasma that contained hexadimethrine to prevent activation. Moreover, the residual antibody reacted with human plasma kallikrein at all stages of purification despite varying degrees of activation (8), giving a reaction of identity by immunodiffusion. Further, antiserum precipitated the kallikrein antigen from plasma, neutralized kallikrein activity, and inhibited prekallikrein activation. These properties provide evidence that this antibody is directed against antigenic determinants present on both kallikrein and prekallikrein. Although no precipitin reaction was noted with dog, goat, sheep, cow, rabbit, or rat plasma, monkey plasma reacted with the antihuman kallikrein antibody and showed a line of identity with human plasma expected from the close evolutionary relationship.

In many cases, antibodies directed against enzymes do inhibit their respective antigens' catalytic action; i.e. they are neutralizing antibodies. When kallikrein was incubated with the antiserum, only a partial inhibition $(30 \%)$ was observed for the esterolytic activity of the enzyme, yet the antisera inhibited $91.5 \%$ of the kallikrein proteolytic activity. The incomplete inhibition of esterolytic activity is similar to the observations by Harpel (25) that enzymes which interact with $\alpha_{2}-\mathrm{M}$, e.g. thrombin (26), kallikrein $(27,17)$, and trypsin (28), form a complex in which the enzymes retain their ability to degrade low molecular weight substrates while their proteolytic activity is lost. In contrast, $C \overline{1}$ inactivator inhibits the proteolytic and esterolytic actions of kallikrein equally $(23,29)$.

Antiserum prepared against kallikrein was an inhibitor of the activation of prekallikrein, as determined by either the esterase or protease activity. In the case of kaolin activation, the responsible molecule is probably $\mathrm{XII}_{a}$, since a similar degree of inhibition was noted when purified factor XII a was employed. Activation by Hageman factor fragments, PKA, and large activator at a similar antiserum-to-prekallikrein ratio was less complete. Thus, the degree of protection of the cleavage site in the prekallikrein molecule upon complexing with the antibody appears to be related to the size of the activator molecule. However, this difference is relative rather than absolute, since at higher concentrations of anti- serum, virtually complete inhibition occurs regardless of the activator used.

Human plasma contains kallikrein inhibitors $(17,27$, 29) that inhibit kallikrein after kaolin activation or added active kallikrein. Kinetic evidence suggests that kallikrein forms stochiometric complex with $\mathrm{C}_{1}^{-1}$ inactivator (29). Barrett and Starkey (30) have concluded that $\alpha_{2}-\mathrm{M}$ forms a stoichiometric complex with different proteases. Immunoelectrophoretic results (Fig. 5) with antikallikrein antibody indicate that kallikrein incubated with plasma produces a new species distinct from free kallikrein but with migration similar to $\bar{C} \overline{1}$ inactivator, detected by a specific antibody. To identify which inhibitor was responsible for the formation of the interaction product, each inhibitor, after partial purification by gel filtration, was separately interacted with purified kallikrein. Only the preparation containing $\mathrm{C} \overline{1}$ inactivator formed a new precipitation arc with kallikrein. This component may represent a complex between the enzyme and inhibitor or an altered kallikrein. Further experiments are needed to clarify the nature of this component. Similar interaction products may be formed in vivo during activation of this system.

Formation of a complex between purified kallikrein and $\alpha_{2}-\mathrm{M}$, either partially purified or as present in normal plasma, could not definitely be demonstrated by immunoelectrophoresis with either antikallikrein or anti$\alpha_{2}-\mathrm{M}$. However, the product of the interaction between kallikrein (mol wt 90,000) and $\alpha_{2}-\mathrm{M}$ ( $m o l$ wt 700,000) might have identical electrical mobility to that of the free $\alpha_{2}-\mathrm{M}$, as has been seen with chymotrysin (31). When the mixture of kallikrein and partially purified $\alpha_{2}-\mathrm{M}$ were subjected to immunoelectrophoresis and the plates developed with antikallikrein, a marked decrease in the strength of the precipitin line is observed (Fig. 7). This finding suggests that part of the kallikrein has been bound by $\alpha_{2}-\mathrm{M}$, thus diminishing the concentration of free kallikrein. However, the complexed kallikrein is not detected by the kallikrein antibody, probably because of decreased availability of antigenic site in the complex.

It is generally agreed that $\mathrm{C} \overline{1}$ inactivator is a major inhibitor of kallikrein in plasma and that $\alpha_{2}-\mathrm{M}$ also inhibits kallikrein, and especially its proteolytic activity $(17,23,27)$. Whether $\alpha_{1}$-AT is also an inhibitor of kallikrein is controversial $(32,23)$. McConnell (17), using the three inhibitors separated from normal plasma by gel filtration, demonstrated inhibition by both $\mathrm{C} \overrightarrow{1}$ inactivator and $\alpha_{2}-\mathrm{M}$ of kallikrein proteolytic activity and also weak inhibition by $\alpha_{1}$-AT. In the present investigation, the percent of the total plasma inhibitory capacity for kallikrein esterase activity was calculated to be $68.5 \%$ for $\mathrm{C}_{\overline{1}}$ inactivator, $13.7 \%$ for $\alpha_{2}-\mathrm{M}$, and $17.8 \%$ for $\alpha_{1}-\mathrm{AT}$. In our study, as well as in that of McConnell, 
the $\alpha_{2}-\mathrm{M}$ is a relatively poor inhibitor of esterase activity of kallikrein (25). Harpel has documented that kallikrein can cleave $\alpha_{2}-\mathrm{M}$, presumably allowing subsequent complex formation between inhibitor and enzyme (25).

The preparation of the antibody to kallikrein made possible the development of a radial immunodiffusion assay for plasma kallikrein antigen, which is present in noncontacted plasma as prekallikrein. The specificity of the assay is evident, since Fletcher factor-deficient plasma contained no kallikrein antigen when IgG-absorbed antibody was used. In contrast, Hageman factordeficient plasma gave a value in the range of normal.

Liver disease results in markedly decreased prekallikrein activity $(4,15)$. This finding might be due to decreased function of an abnormal prekallikrein or an absolute decrease in the amount of prekallikrein synthesized. There has been some evidence indicating that the liver is the site for plasma prekallikrein biosynthesis $(10,33)$. Depression of plasma prekallikrein in hepatocellular disease has been documented $(6,10)$. In mild alcholic cirrhosis, functional and antigenic kallikrein are significantly depressed and closely correlated. The relationship between antigen and esterase activity is similar to that in normal subjects. However, the plasma of patients with severe liver disease in whom levels of prekallikrein have been decreased to $8 \%$ of normal, as measured by esterase assay, contain about $40 \%$ of the normal prekallikrein antigen (Fig. 9). The absence of the correlation between kallikrein function and antigen in severe liver disease suggests that although synthesis is depressed, the livers of some of these patients may be synthesizing a nonfunctional kallikrein. Examination of the prekallikrein antigen present in the plasma from one of the severe cirrhosis patients revealed a weak precipitin arc. However, no significant difference in the position of the arc after immunoelectrophoresis was noted when compared to normal plasma.

\section{ACKNOWLEDGMENTS}

This work was supported in part by Grant HL16642 from the National Institutes of Health and by a grant from the American Heart Association.

\section{REFERENCES}

1. Cotran, R. S., and G. Majno. 1964. A light and electron microscopic analysis of vascular injury. Ann. N.Y. Acad. Sci. 116: 750-764.

2. Kaplan, A. P., and K. F. Austen. 1970. A pre-albumin activator of prekallikrein. J. Immunol. 105: 802-811.

3. Cochrane, C. G., and K. D. Wuepper. 1971. The first component of the kinin-forming system in human and rabbit plasma. J. Exp. Med. 134: 986-1004.

4. Bagdasarian, A., R. C. Talamo, and R. W. Colman. 1973. Isolation of high molecular weight activator of human prekallikrein. J. Biol. Chem. 248: 3456-3463.

5. Bagdasarian, A., B. Lahiri, and R. W. Colman. 1973.
Origin of the high molecular weight activator of prekallikrein. J. Biol. Chem. 248: 7742-7747.

6. Colman, R. W., J. W. Mason, and S. Sherry. 1969. The kallikreinogin-kallikrein enzyme system of human plasma. Assay of components and observations in disease states. Ann. Intern. Med. 71: 763-773.

7. Webster, M. E., and J. P. Gilmore. 1965. The estimation of kallidins in blood and urine. Biochem. Pharmacol. $14: 1161-1163$.

8. Colman, R. W., L. Mattler, and S. Sherry. 1969. Studies of the prekallikrein (kallikreinogen)-kallikrein enzyme system of human plasma. I. Isolation and purification of plasma kallikreins. J. Clin. Invest. 48: 11-21.

9. Wuepper, K. D. 1972. Biochemistry and biology of plasma kinin-forming system. In Inflammation Mechanism and Control. I. H. Lepow and P. A. Ward, editors. Academic Press, Inc., New York. 93-117.

10. Wong, P., R. W. Colman, R. Talamo, and B. M. Babior. 1972. Kallikrein-brandykinin system in chronic alcoholic liver disease. Ann. Intern. Med. 77 : 205-209.

11. Groves, W. E., F. C. David, Jr., and B. H. Sells. 1968 Spectrophotometric determination of microgram quantities of protein without nucleic acid interference. Anal. Biochem. 22: 195-210.

12. Lowry, D. H., N. J. Rosebrough, A. L. Farr, and R. J. Randall. 1951. Protein measurement with the Folin phenol reagent. J. Biol. Chem. 193: 265-275.

13. Siegelman, A. M., A. S. Carlsen, and T. Robertsen 1962. Investigation of serum trypsin and related substances. I. The quantitative demonstration of trypsinlike activity in human blood serum by a micromethod. Arch. Biochem. Biophys. 97: 159-163.

14. Colman, R. W., L. Mattler, and S. Sherry. 1969. Studies on the prekallikrein(kallikreinogen)-kallikrein enzyme system of human plasma. II. Evidence relating the kaolin-activated arginine esterase to plasma kallikrein. $J$. Clin. Invest. 48: 23-32.

15. Talamo, R. C., E. Haber, and K. F. Austen. 1969. A radioimmunoassay for bradykinin in plasma and synovial fluid. J. Lab. Clin. Med. 74: 816-827.

16. Davis, B. J. 1964. Disc electrophoresis. II. Method and application to human serum protein. Ann. N. Y. Acad. Sci. 121: 404-427.

17. McConnell, D. J. 1972. Inhibitors of kallikrein in human plasma. J. Clin. Invest. 51: 1611-1623.

18. Scheidegger, J. J. 1955. Une micro-méthode de immunoélectrophorèse. Int. Arch. Allergy Appl. Immunol. 7: 103-110.

19. Ouchterlony, ठ. 1953. Antigen-antibody reactions in gels. IV. Type of reactions in coordinated systems of diffusion. Acta Pathol. Microbiol. Scand. 32: 231-240.

20. Mancini, G., A. O. Carbonaro, and J. F. Heremans. 1965. Immunochemical quantitation of antigen by single radial immunodiffusion. Immunochemistry. 2: 235-254.

21. Snedecor, G. W., and W. G. Cochran. 1967. Statistical methods. 6th edition. Iowa State University Press, Ames, Iowa. 159.

22. Harpel, P. C. 1971. Separation of plasma thromboplastin antecedent from kallikrein using the plasma $\alpha_{2}$-macroglobulin kallikrein inhibitors. J. Clin. Invest. 50: 2084-2090.

23. Schreiber, A. D., A. P. Kaplan, and K. F. Austen. 1973. Plasma inhibitors of the components of the fibrinolytic pathway in man. J. Clin. Invest. 52: 1394-1401.

24. Kaplan, A. P., A. B. Kay, and K. F. Austen. 1972. A prealbumin activator of kallikrein. III. Appearance 
of chemotactic activity for human neutrophils by the conversion of human prekallikrein to kallikrein. J. Exp. Med. 135: 81-97.

25. Harpel, P. C. 1973. Studies on human plasma $\alpha_{z-}$ macroglobulin-enzyme interactions. Evidence for proteolytic modification of the subunit chain structure. $J$. Exp. Med. 138 : 508-521.

26. Lanchantin, G. F., M. L. Plesset, J. A. Friedman, and D. W. Hart. 1966. Dissociation of esterolytic and clotting activities of thrombin by trypsin-binding macroglobulin. Proc. Soc. Exp. Biol. Med. 121: 444-449.

27. Harpel, P. C. 1970. Human plasma $\alpha_{2}$-Macroglobulin: an inhibitor of plasma kallikrein. J. Exp. Med. 132: 329-352.

28. Mehl, J. W., W. O'Connell, and J. DeGroot. 1964. Macroglobulin from human plasma which forms an enzymatically active compound with trypsin. Science (Wash. D. C.). 145 : 821-822.

29. Gigli, I., J. W. Mason, R. W. Colman, and K. F.
Austen. 1970. Interaction of plasma kallikrein with the C $\overline{1}$ inhibitor. J. Immunol. 104: 574-581.

30. Barrett, A. J., and P. M. Starkey. 1973. The interaction of $\alpha_{2}$-Macroglobulin with proteases. Characteristics and specificity of reaction and a hypothesis concerning its molecular mechanism. Biochem. J. 133: 709724.

31. Ohlsson, K. 1971. Interactions between bovine $\alpha$-chymotrypsin and the protease inhibitors of human and dog serum in vitro. Scand. J. Clin. Lab. Invest. 28: $5-11$.

32. Colman, R. W., and B. Mitchell. 1972. Specificity of inhibitors lacking in alpha $a_{1}$ antitrypsin deficiency and hereditary angioedemia toward human proteolytic enzymes. Clin. Chim. Acta. 39: 5-14.

33. Werle, S., R. Vogel, and G. Kaliampetsos. 1963. Utber das Kallikrein der Darmwand und seine Beziehung zum Blutkallekreinehalt bei Störungen der Darmfunktion. World Congr. Gastroenterol. Proc. 2: 778-783.

1454 A. Bagdasarian, B. Lahiri, R. C. Talamo, P. Wong, and R. W. Colman 